\title{
The Circular Economy: Swings and Roundabouts?
}

\author{
Neal Millar, Eoin McLaughlin, Tobias Börger \\ School of Geography and Sustainable Development, University of St Andrews, UK
}

Abstract: In the last few decades the Circular Economy has increasingly been advertised as an economic model that can replace the current "linear" economy whilst addressing the issues of environmental deterioration, social equity and long-term economic growth with the explicit suggestion that it can serve as a tool for Sustainable Development. However, despite the individual prominence of the Circular Economy and Sustainable Development in the academic and wider literature, the exact relationship between the two concepts has neither been thoroughly defined nor explored. The consequent result is various inconsistencies occurring across the literature regarding how the Circular Economy can serve as a tool for Sustainable Development and an incomplete understanding of how its long-term effects differ from those of the "linear" economy. A literature review was conducted to interpret the current conceptual relationship between the Circular Economy and Sustainable Development. The review highlights numerous challenges concerning conceptual definition, economic growth and implementation that inhibit the use of the Circular Economy as a tool for Sustainable Development in its current form. The review concludes by providing suggestions for how research concerning the Circular Economy should proceed if it is to provide a potential approach for achieving Sustainable Development.

JEL-codes: O13, O44, Q01, Q53, Q56

Key words: Circular Economy, Sustainable Development, Linear economy, Social equity, Economic growth, Environmental degradation 


\section{Introduction}

There is now a widespread consensus that current human consumption and production practices are having a detrimental effect on environmental quality, social equity and long-term economic stability (Rees, 2010; Vlek and Steg, 2007; Anand and Sen, 2000; Schaefer and Crane, 2005). The current "linear" material and energy flow model, ${ }^{1}$ as the medium for these practices, has therefore been identified as a contributing factor to these problems (Bonviu, 2014; Esposito et al, 2017: Korhonen et al., 2018a). Furthermore, there exists a challenge to devise a model for Sustainable Development that encourages economic prosperity without simultaneously degrading the environment or diminishing social equity (Dale 2012; Buchs and Koch, 2017). As such the concept of the Circular Economy has gained favourable traction with academics, policymakers and businesses as an alternative model that can achieve patterns of production and consumption that have a negligible environmental impact whilst still encouraging growth (Andersen, 2007; Geng and Doberstein, 2008; Webster, 2015).

However, despite the Circular Economy being frequently advocated and acknowledged as a tool or strategy for achieving Sustainable Development through encompassing the three pillars of environmental, economic and social development, (Xue et al., 2010; Yuan et al., 2006; Ghisellini et al., 2016; Korhonen et al., 2018a), the conceptual relationship between the two notions remains ambiguous and has yet to be thoroughly defined. This is reinforced by authors who posit that the Circular Economy is viewed as an approach to "implement the much discussed concept of Sustainable Development" (Kirchherr et al., 2017: 222) and is "an approach to [...] promote Sustainable Development" yet concurrently highlight the deficiency in comprehension between the two concepts(Korhonen et al., 2018b: 544). Most explicitly, Schroeder et al. (2018) suggest that the Circular Economy can directly help attain a variety of the UN Sustainable Development Goals (SDGs). However, numerous contradictions and knowledge gaps exist regarding how the Circular Economy can improve social equity, promote economic growth and permanently reduce the rate of extraction of raw materials by closing material loops. This has led to the possibility of the Circular Economy, although promoted as an alternative model which can be used as a strategy for Sustainable Development, being undifferentiated from the linear economy in the sense that it could ultimately produce similar outcomes. Whilst other reviews have briefly discussed the connection between the Circular Economy and Sustainable Development (Ghisellini et al., 2016, Geissdoerfer et al., 2017; Kirchherr et al., 2017), there have been no reviews that explicitly analyse how the Circular Economy can serve as a tool for achieving Sustainable Development. A possible exception to this is the review of the Circular Economy and its limitations by Korhonen et al., (2018a) who emphasise the need for an analysis of the concept from the perspective of Sustainable 
Development. However, as acknowledged in that contribution, the authors offer a critique only from the perspective of environmental sustainability, neglecting social and economic aspects. In addition, although the potential for the Circular Economy to assist in achieving several of the SDGs is discussed by Schroeder et al., (2018), this is contingent on multiple contested assumptions the present review aims to illuminate.

The objective of this review of Circular Economy literature is to examine the relationship between the concepts of the Circular Economy and Sustainable Development. The review critically analyses the ability of the Circular Economy, as it is currently presented amongst numerous literature subfields, to encompass the components of Sustainable Development and attain the aforementioned SDGs. The review highlights that the theoretical association between the Circular Economy and Sustainable Development has not been adequately established and as such the subsequent discourse is failing to address many of the same issues which the linear economy has received criticism for. The proposed reasons for this are that there have been few attempts to classify the Circular Economy in relation to Sustainable Development, an absence of interdisciplinary collaboration to understand the scientific and conceptual workings of the Circular Economy and a lack of coherence regarding how to implement the Circular Economy. Therefore, without further research it could be suggested that the Circular Economy, as it is currently understood, could continue to cause environmental degradation albeit at slower pace, maintain a reliance on the extraction of virgin resources for continuous economic growth and not improve social equity.

The review proceeds as follows: Section 2 provides a brief overview of the concepts of Sustainable Development (2.1) and the Circular Economy (2.2). Section 3 assesses the validity of suggestions in the literature advocating the Circular Economy as a tool for Sustainable Development through debates concerning conceptual understanding (3.1), biophysical barriers (3.2), economic growth (3.3), social equity (3.4) and implementation (3.5). The review concludes with a summary of the key findings and suggestions for the future direction of research into the Circular Economy regarding Sustainable Development. Finally, a trenchant narrative exists throughout that emphasises the key message of this review that the concept of a Circular Economy, through its current comprehension, must at most be understood as simply a more environmentally sustainable model than the "linear" economy and not as an optimal tool for Sustainable Development, as it is frequently portrayed. 


\section{The Rise of the Circular Economy}

As this review seeks to analyse the current understanding of how Sustainable Development is being pursued in the Circular Economy literature, it is first important to briefly establish the conceptual background of both Sustainable Development (2.1) and the Circular Economy (2.2) on which to base a review of the debates in Section 3.

\subsection{Sustainable Development}

Despite concerns about the sustainable development of humans on Earth being an age-old enduring thought, the phrases "sustainability" and "sustainable development" have only gained notoriety in the last half century (Redclift, 2005). Whilst the publication of The Limits to Growth (Meadows, 1972) was a thought provoking contemplation that partially galvanised numerous debates concerning the degradation of the environment at the expense of continuous economic growth (Dasgupta and Heal, 1974; Solow; 1974; Stiglitz; 1974), it is suggested that these debates remained relatively stagnant until the publication of Our Common Future in 1987 (Brundtland, 1987; Sachs, 2015; Baker, 2012). The aforementioned report was an output of global representatives' environmental concerns and produced the most widely known definition of sustainable development as "development that meets the needs of the present without compromising the ability of future generations to meet their own needs" (Brundtland, 1987: 3). As such the report highlighted the need to balance environmental, social and economic dimensions of human activity although the way in which this is conceptualised is contested and has therefore resulted in numerous models that each have a different perception of how Sustainable Development should be approached (Robinson, 2004). For example, an early suggestion for a model which reflects Sustainable Development was the "three pillared" or "three-legged stool" model which emphasised that all three dimensions must remain equally balanced otherwise any potential long-term sustainability would not be achievable (Young, 1997). However as noted by various authors, this model implies that the three dimensions are separate from one another (Dawe and Ryan, 2003). On the other hand, as illustrated in Figure 1, the conceptual model of three overlapping circles or the Venn diagram has been applied to emphasise the interconnectedness of the three aspects of Sustainable Development (Flint, 2013). The model highlights that the effects of one dimension will have consequences for the other two dimensions and that the three must be seen as interconnected to meet the requirements of Sustainable Development. Yet this conceptualisation has also been criticised for "not recognising the full integration of the environmental, social and economic dimensions" (Moir and Carter, 2012: 3). 
More recently, the conceptualisation of Sustainable Development has been expressed in the formulation of the Sustainable Development Goals (SGDs) which are a collection of 17 global goals set by the United Nations General Assembly whose aim is to meet the environmental, political and economic challenges facing our world (UN, 2012). The goals cover issues including energy, economic growth, consumption and production, and climate action and although each has their own separate targets, the goals are interdependent. ${ }^{2}$

\section{[Figure 1]}

Correspondingly, there now exists a myriad of models that attempt to conceptualise Sustainable Development with each having a different interpretation of how the three dimensions should be considered. The result of this ambiguity is that it has complicated how Sustainable Development is pursued and as such its conceptual understanding differs across the literature (Blewitt, 2016). Furthermore, it is important to highlight that recent reviews have also criticised the use of the environment, economy and society as dimensions and instead insist that these are replaced with satisfying human needs, ensuring social equity and respecting environmental limits (Holden, 2017: 2). Despite this, there is a widespread acknowledgement that for Sustainable Development to occur, one dimension should not be pursued at the expense of the other two (Sachs, 2015).

In addition, the commonly utilised Brundtland (1987) definition emphasised both the importance of meeting the needs of the global population and of intergenerational equity. However, many criticisms also arose, particularly in relation to precisely what the notion of "needs" comprised of and as such the ambiguity of the term (Lele, 1991; Mebratu, 1998). Nevertheless research focused on Sustainable Development has, in general, had an inherent recognition that for a tool or practice to be considered conducive with the principles of Sustainable Development, it must not inhibit the ability for future generations to live in conditions afforded to the present generation (Broman and Robert, 2017). Therefore, in combination with the previous element, advancements that inhibit the capacity of future generations to meet their own "needs", due to an imbalance of the three dimensions, will not achieve Sustainable Development.

Therefore it is commonly accepted that the linear or "take, make, dispose" economy, the current dominant material and energy flow model, where raw materials are extracted, manufactured, used and then discarded to induce economic growth, cannot lead to Sustainable Development due its damage to the environment and its inability to promote global social equity (Frosch and Gallopoulos, 1989; Andersen, 2007; Hoekstra and Wiedmann, 2014; Constanza et al., 
2014). Furthermore, it is debated as to whether it is indeed possible for continuous economic growth to simultaneously coexist with protecting the environment and improving global social equity (Jackson and Senker, 2011; Kallis, 2011). Yet despite these concerns, the concept of the Circular Economy is being promoted as a model that can provide the solution (Ellen MacArthur Foundation, 2017; Webster, 2015).

\subsection{The Circular Economy}

The origins of the Circular Economy are not attributed to a particular author, however it has been commonly suggested (Ghisellini et al., 2016; Andersen, 2007; Lieder and Rashid, 2016) that the general idea emerged from the work of Boulding (1966: 5) who proposed that the Earth was a closed system with "limited assimilative capacity and as such the economy and environment must coexist in equilibrium". This general understanding has since been advanced by numerous schools of thought including environmental economics (Pearce and Turner, 1990), industrial ecosystems (Jeliniski et al., 1992); cleaner production (Stevenson and Evans, 2004); product-service systems (Tukker, 2015); biomimicry (Benyus, 1997); the performance economy (Stahel, 2010); ecoefficiency (Haas et al., 2015); cradle to cradle design (Braungart et al., 2007); regenerative design (Lyle, 1996) and industrial ecology (Graedel and Allenby, 2003) to incorporate the idea of a closedloop economy.

Despite its academic origins, it has been suggested that the contemporary conceptualisation of the Circular Economy and its practice has been predominantly advanced by businesses and policymakers (Korhonen et al., 2018a). As such, although no universal definition of the concept exists in the literature both within and between schools of thought, the Circular Economy is generally understood by the business world as a model that is "restorative and regenerative by design, and aims to keep products, components, and materials at their highest utility and value at all times" (Ellen MacArthur Foundation, 2017: 1, Stahel 2016). In addition, the model is commonly interpreted as a "positive development cycle" that "preserves and enhances natural capital, optimises resource yields, and minimises system risks" (Ellen MacArthur Foundation, 2017: 1). Moreover, the critical component of the Circular Economy is that it aims to identify an optimal level of loop closing to create a minimum need for extracting virgin raw materials due to the processes of minimising waste, extending product life, maintaining materials at their highest level, optimising reuse and utilising energy sources such as biomass as a strategy to close material loops via ecosystem processes (Webster, 2015, Stahel 2016). Furthermore, in terms of implementation of the Circular Economy, the concept has been most notably promoted by the EU, who invested $€ 650$ million into their package to transition to a Circular Economy, and China who is the first 
country to adopt a law for the Circular Economy (EMF, 2013; European Commission, 2014; European Commission, 2015; CIRAIG, 2015). In parallel there has also been growing uptake of the Circular Economy amongst businesses with foundations such as the Ellen MacArthur Foundation (2017) promoting its benefits to its "CE100 companies" including Dell, Coca-Cola and IKEA although the extent to which these companies have done so is unclear.

Although section 3.1 highlights the lack of an appropriate definition of the Circular Economy pertaining to Sustainable Development, it is important to establish a working definition in order to contextualise the debates of this review. Therefore, the review utilises one of the few definitions that references Sustainable Development and all of its major components, synthesised by Kirchherr et al., (2017: 229) who suggest the Circular Economy to be "an economic system that replaces the 'end of life' concept with reducing, alternatively reusing, recycling and recovering materials in production/distribution and consumption processes. It operates at the micro level (products, companies, consumers), meso level (eco-industrial parks) and macro level (city, region, nation and beyond), with the aim to accomplish sustainable development, thus simultaneously creating environmental quality, economic prosperity and social equity, to the benefit of current and future generations. It is enabled by novel business models and responsible consumers". It is also important to note, that the ambiguity and diversity of understandings surrounding the Circular Economy has resulted in the concept having a myriad of definitions, but concurrently being referred to in numerous ways including as a "new economic paradigm" (Geissdoerfer et al., 2017), an "industrial model" (Yuan et al., 2006) and a "new business model" (Ghisellini et al., 2016). Therefore although the definition employed describes the Circular Economy as "an economic system", as with other authors including Korhonen et al., (2018a) we use the term "material and energy flow model". The remainder of the review therefore seeks to analyse the literature to understand if the grounds for promoting the Circular Economy as a tool for Sustainable Development have theoretical and factual support.

\section{The Circular economy as a Tool for Sustainable Development}

The primary suggested fault of the so called "linear economy" in achieving sustainable development is that the pursuit of continuous economic growth is attained at the price of environmental degradation with an unknown understanding of whether this is improving social equity (Andersen, 2007). Therefore, the Circular Economy, to be the model for Sustainable Development, should address these issues. This section examines the existing Circular Economy literature with regards to the definition of the concept (3.1), the biophysical barriers (3.2), economic growth (3.3), social equity (3.4) and implementation (3.5) to challenge the proposition 
that implementing the Circular Economy is facilitating a move towards Sustainable Development and illustrate that in fact it suffers from the same issues associated with the "linear" economy.

\subsection{Defining Concepts}

As emphasised in Section 2.1, the concept of Sustainable Development has notoriously been criticised for being too ambiguous and vague the result of which being a loss of momentum (Connelly, 2007) and it being reduced to a buzzword (Rist, 2007). However, the principles of Sustainable Development are still considered to be important and although constantly critiqued, any real form of Sustainable Development will still involve adhering to these principles (Holden et al., 2017). Therefore, it could be inferred that for the Circular Economy to act as a tool for Sustainable Development, its definition should address the notions of respecting environmental limits, social equity and economic prosperity in one form or another.

In relation, due to the theoretical underpinnings of the Circular Economy, it has been advocated within the academic literature across numerous journals including Resources Conservation and Recycling (Xue et al., 2010), Ecological Economics (Korhonen et al., 2018a), the Journal of Cleaner Production (Ghisellini et al., 2016) and the Journal of Industrial Ecology (Schroeder et al., 2018) as not only a model to reduce environmental impact but as a tool for achieving Sustainable Development due to its suggested ability to encompass its three classic components. For example, Xue et al., (2010: 1298) suggest that the Circular Economy “is the outcome of over a decade's efforts to practice Sustainable Development by the international economies and is the detailed approach towards Sustainable Development". Yuan et al. (2006: 5) suggest that "it is widely recognised that the Circular Economy could help achieve Sustainable Development". In addition, as highlighted by both Ghisellini et al., (2016) and Kirchherr et al., (2017), Sustainable Development has been frequently advocated as the main aim of the Circular Economy across a wide range of literature. Yet despite this, a detailed account of how the Circular Economy can encompass the environmental, economic and social dimensions of Sustainable Development has not been put forward - hence, in part, the purpose of this review.

In addition, whilst Schroeder et al., (2018) suggest that the Circular Economy can contribute directly to achieving several of the SDGS (SDG6 (clean water and sanitation), SDG7 (affordable and clean energy), SDG 8 (decent work and economic growth), SDG12 (responsible consumption and production) and SDG15 (life on land)) this is dependent on the current understanding of the Circular Economy within the literature, which as this review emphasises, is filled with knowledge gaps and contestations that must first be addressed. 
In their review of 114 definitions of the Circular Economy, Kirchherr et al., (2017) revealed through a comprehensive coding technique that of all definitions sampled, only $11 \%$ explicitly included notions of Sustainable Development. Whilst it may not be expected for the definitions to contain the term explicitly due to its numerous criticisms, the review also shows that only $13 \%$ of definitions refer to all three dimensions of Sustainable Development. As such, it is uncertain as to how an understanding of the Circular Economy that does not encompass more than one aspect of Sustainable Development can result in a model that is to be considered sustainable.

Similarly, Geissdoerfer et al., (2017: 764) suggest that many authors do not consider the three dimensions of Sustainable Development "holistically" and instead indicate that the majority of considerations are given to the restoration of the environment over attention to economic prosperity and social equity. This is also supported by Lieder and Rashid (2016: 46) who argue that "discussions around the Circular Economy are done from an environmental perspective leaving economic benefits missing". Yet in direct contrast, Kirchherr et al., (2017) show that economic prosperity receives most attention (46\% of definitions) whilst environmental was only referred to in 38\% of definitions. Perhaps most revealing of all, Kirchherr et al., (2017) stress that of all 114 definitions, only $1 \%$ made reference to any notion of temporal scale or the concept of future generations. This finding is supported by Geissdoerfer et al., (2017: 766) who suggested that time dimensions are "excluded from most Circular Economy discussion". This therefore can be considered problematic as it emphasises the lack of vision for the future and suggests the momentum carrying the Circular Economy is to implement it without foresight and any consideration of intergenerational equity.

Furthermore, numerous authors have remarked on the "blurriness" of the concept due to it being applied and understood from the perspective of numerous schools of thought (Yuan et al., 2008; Lieder and Rashid, 2016; Sauve et al., 2016; Murray et al., 2017). For example, Lieder and Rashid (2016: 37) point out that "there are various possibilities for defining the Circular Economy" whilst Yuan et al., (2008: 5) write that "there is no commonly accepted definition of the Circular Economy". This therefore provides a problem when trying to promote the idea as a tool of achieving Sustainable Development - a concept itself which contains a myriad of definitions.

Therefore, whilst it could be debated that the definition of the Circular Economy is not important so much as the direction in which the discussion is moving, as emphasised by Kirchherr et al., (2017: 221), "a concept with various understandings may ultimately collapse or remain in deadlock due to permanent conceptual contention". As such if the aim of the Circular Economy is to provide a new material and energy flow model that can achieve Sustainable Development, a consistent definition that adheres to the three dimensions of Sustainable Development and the 
notion of providing for future generations must be established. Whilst Kirchherr et al., (2017) have created a sufficient definition that meets this criterion (as displayed in Section 2.2), it is only the first of its kind and must be widely adopted across the literature if it is to successfully produce a meaningful impact. However, as the remaining sections of this review point out, the current lack of coherence between the various parties involved concerning the notion of the Circular Economy and Sustainable Development, suggest this will not be straightforward.

\subsection{Biophysical Barriers of the Circular Economy}

As mentioned in Section 2.2, the Circular Economy has been primarily advanced and promoted by policy makers, business consultants and non-governmental organisations. As a result, Gregson et al., (2015: 20) suggest the circular economy to be "a diverse bundle of ideas which have collectively taken hold" and has "more often been celebrated than critically interrogated". This is furthered by Korhonen et al., (2018a: 37) who argue that "the scientific and research content of the Circular Economy concept is superficial and unorganised". Moreover, the authors suggest that the Circular Economy appears to be "a collection of vague and separate ideas from several fields and semi-scientific concepts" and therefore suggest that the scientific principles regarding the Circular Economy have lacked any significant analysis, including from the perspective of Sustainable Development (Korhonen et al., 2018a: 38).

A primary example of this concerns a critique of the key tenet of the Circular Economy, that the system is closed looped. As proposed by Georgescu-Roegen (1971), the second law of thermodynamics means that the process of recycling will everlastingly need energy and will also always create waste and side-products due to increasing entropy. Therefore, closed material loops are practically and theoretically impossible. This is reflected in Korhonen et al., (2018a: 40) who suggest that if the expansion of the physical scale of the global economic system is not kept in balance, even the so-called "closed loop" processes utilised by the Circular Economy will eventually result in "unsustainable levels of resource depletion, pollution and waste generation". Whilst this process may take a long time to occur, the suggested reality would be that the negative environmental impact will ultimately be the same as that of the linear economy, albeit occurring over a much greater time period. Although it could be argued that a closed-loop system would provide a more sustainable flow of material, this is not the same as Sustainable Development as one dimension is pursued over another and there is no comprehensive consideration of future generations.

It is also apparent that there is an inconsistency within the Circular Economy literature between those who continue to promote the system as having an ability to be completely or nearly closed- 
looped (e.g. Geng and Doberstein, 2008; Matthews and Tan, 2011) and those who recognise that the system as a more sustainable model than the linear economy with optimal rather than maximum levels of loop closing (e.g. Korhonen et al., 2018a). In addition to the thermodynamic law that emphasises the impossibility of loop closing, Haas et al., (2015) highlight two structural barriers which further limit the ability to close material loops. The first of these concerns the issue that a vast proportion of materials accrues in use stocks (buildings, durable goods and infrastructure) and that this trend is increasing, especially amongst many emerging economies. Therefore, as long as this trend continues, which appears likely due to the current and forecasted socioeconomic metabolism, not even high rates of recycling can improve overall circularity (Haas et al., 2015; Pauliuk et al., 2011; Pauliuk, 2018). Secondly, the authors point out the high volume of materials, in particular fossil-fuels, utilised for energy generation. Whilst these materials are harnessed for this purpose, it further reduces an ability to close material loops and instead only allows an optimal level of loop closing to be achieved.

In addition to these limits, Allwood (2014) emphasises that there is no evidence to suggest that secondary production can completely displace primary production. In an in-depth analysis concerning the life-extension of the major material classes, the author highlights that using current technology, it is not possible to break down some wastes or to purify certain liquids. Whilst the author concedes that advances in technology may one day make it conceivable that all atomic structures could be separated, the author also argues that the process would require more energy than new production and as such counteract any environmental benefits. Therefore, Allwood (2014) suggests that until the emergence of a technology which has the ability to break down complex atomic structures, a completely closed-loop system is impossible to be achieved as waste will still be generated and hence secondary production cannot displace primary production until this point.

Similarly, as acknowledged by Ghisellini et al., (2016), another key tenet of the Circular Economy is that end-products are designed to be long-lasting, so they can be repeatedly reused, thus reducing the dependence of continued extraction of finite virgin materials. However, as noted by Korhonen et al., (2018a), there is presently an expansive knowledge gap concerning the aftereffects of material flows and as such by lengthening the lifespan of a product, it could create subsequent systems that endanger permanent sustainability. Therefore, by extending the lifecycle of a product it may do more environmental damage than if it were to simply maintain its short lifetime. Hence this highlights that given the uncertain long-term effects of extending product lifetimes, there is no assurances to suggest that this is a better alternative to the current model. 
Although Korhonen et al., (2018a) are amongst the first to raise awareness of the lack of critical interrogation of the scientific foundations of the Circular Economy, the authors intermittently switch between the terms "environmental sustainability" and "Sustainable Development", despite the concepts being conceptually different. As such the scientific challenges raised by the authors are primarily within the context of only environmental sustainability, not Sustainable Development. Whilst the issues raised require attention, it is clear that there may still be several inherent scientific complexities associated with Sustainable Development that lack consideration, which further emphasises the need for an interdisciplinary approach. Without greater scientific understanding and critique, there is insufficient evidence to suggest the Circular Economy can reduce extraction of raw materials in the long term. Consequently, the only difference from the linear model would be that the negative environmental impact will take longer to occur.

\subsection{Economic Growth}

As highlighted in Section 2.1, a widespread criticism of the current "linear" model is that it pursues economic growth despite resulting environmental degradation. Therefore, as pressure is increasing regarding how economies respond to this, the Circular Economy has become gradually more appealing to businesses and policy makers as it is promoted as a model that can "decouple" economic growth from resource use (Ellen MacArthur Foundation, 2017). Furthermore, authors such as Matthews and Tan (2011) and Su et al., (2013) advocate that the displacement of primary production by secondary production will still stimulate economic growth and argue that economic growth following a Circular Economy model will indeed be greater in the long term in comparison to the growth forecasts of current linear models. This illustrates the current narrative of the Circular Economy as a model that stimulates growth with negligible environmental damage and as such explains the common "win-win" catchphrase that is increasingly being associated with the Circular Economy (European Commission, 2015).

However, there have been several recent criticisms that have questioned the reality of this "win-win" situation. For example, Allwood (2014: 466) examined the possibility of a Circular Economy in a globalised world where consumption is growing and as such noted "if demand is growing, the circle cannot remain closed”. In parallel, McMillan et al., (2012) highlight that it is market forces that principally dictate displacement and as such argue that if consumption continues to increase, there is no rationale as to why market forces would allow for secondary production to accomplish complete displacement of primary production. The authors suggest that whilst it could be conceived that there will be a reduction in rates of raw material extraction, there is no evidence that this is guaranteed. Correspondingly, Zink and Geyer (2017) have criticised the existing 
literature for omitting economic aspects of the Circular Economy. The authors discuss the issue of "rebound effects" - a concept that has been widely explored in both industrial ecology and energy economy literature (Hertwich, 2005; Gillingham et al., 2013). Applying the same logic to the Circular Economy, the authors highlight that as the model works by improving secondary production efficiency, this will decrease production costs and as a result the costs of end-products will also decrease. Therefore, as with energy rebound effects, this will boost consumption, and the total economic-growth could counteract the original environmental benefits caused by increased efficiency. This is supported by Korhonen et al., (2018a: 45) who suggest that it is not evident as to how improving productivity will reduce consumption and therefore propose that unless contemporary patterns of consumption are revised, the Circular Economy "will remain a technical tool that does not change the course of the current unsustainable economic paradigm". The authors further highlight that it is reduced production and altered consumption that is required to reduce environmental impacts, two processes which the Circular Economy does not directly encourage.

In relation, both Allwood (2014) and Zink and Geyer (2017) reference Boulding (1966) who suggested "a circular economy could be achieved if global demand for both the volume and composition of products stabilised". Furthermore, the authors respectively describe this statement as both a "nirvana" and "utopia" that is currently not conceivable given the consumption driven global economies. The authors note that despite Boulding (1966) including this assumption, those who promote the Circular Economy as a form of economic growth that aligns with environmental restoration have failed to recognize this inherent challenge.

In parallel, whilst there have been longstanding and widespread suggestions that other routes of "win-win" sustainable growth have not been fulfilled, for example those regarding improvements in efficiency and technology (Jackson and Senker, 2011), it is curious that these debates have not been as common within Circular Economy literature. Whilst it could be suggested that there has been a lack of awareness across different disciplines, there have been articles on both topics published in the same journal, such as Schneider et al., (2010) and Su et al., (2013), yet despite this, the concerns of sustainable growth have not crossed over and as such this has allowed Circular Economy literature to develop without having to acknowledge these contestations. This illustrates that contradictions concerning the Circular Economy exist not only between disciplines but also within them.

Therefore, despite being the common narrative, it is evident that it is contested as to whether the Circular Economy can stimulate economic growth without degrading the environment. Whilst there are compromised suggestions that environmental damage caused by the Circular Economy 
would be less than that produced by the linear economy, there are no assurances of this due to the possibility of rebound effects. There is justification to contest that a Circular Economy could be a more sustainable form of stimulating economic growth than the linear economy, however, as emphasised throughout the review, this is not the same as Sustainable Development. In addition, it is also viable to suggest that the current criticisms of the Circular Economy simply reiterate the primary obstacle impeding Sustainable Development, that unless technology improves, there is still no consensus on how to achieve economic growth without adversely affecting the environment.

\subsection{Social Equity}

As noted in Section 2.1, the majority of Sustainable Development models emphasise the importance of equally balancing the three dimensions of economic prosperity, environmental protection and social equity. The advancement of social equity refers to, amongst other aspects, the improvement in human rights and social justice. This encompasses not only intra-generational equity including between the global North and South, but also inter-generational equity between the current generation and those to come. Whilst it has been debated that it may not be conceivable for social equity to coexist with environmental and economic dimensions, Robinson (2004: 376) stresses that "social equity is explicit as a dimension". Therefore, as the Circular Economy is being promoted as a tool for Sustainable Development, there should to be some form of framework illustrating the ways in which the model can promote social equity and how it does so whilst incorporating the other two dimensions.

However, as commented by Murray et al., (2017: 22), the Circular Economy literature is "virtually silent on the social dimension". This is supported by Moreau et al., (2017: 500) who also suggest that "there seems to be no clear understanding of the extent to which the Circular Economy could contribute to the promotion of social equity". Whilst it has been acknowledged that restoration of the natural environment and reduction of the extraction and use of finite resources will most likely benefit mankind (Ellen MacArthur Foundation, 2017), there has been no detailed analysis, explicitly for the Circular Economy that empirically supports this. Therefore, Murray et al (2017) submit that the only references to social equity are vague suggestions on how the Circular Economy will improve aspects of this dimension. Furthermore, Geissdoerfer et al., (2017) highlight that of the few papers that mention social aspects, the reference is primarily to job creation and that this also lacks empirical support.

In parallel, there are numerous examples of ambiguous suggestions, primarily found amongst the literature on Chinese implementation, on how the Circular Economy will promote social 
equity. For example, Xue et al., (2013) suggest that the Circular Economy will improve social welfare distribution whilst Feng and Yan (2007: 100) suggest that a Circular Economy helps to "promote social justice". However as noted by Geng et al., (2012), there have been no quantitative studies which support these statements. The authors also note that "the Chinese national Circular Economy standards are absent of any social indicators" and recognise that "more indicators are thus needed to portray the social aspects" (Geng et al., 2012: 221). Therefore, without the creation of a suitable indicator that can not only account for social equity but that also encompasses the other two dimensions, it is unclear as to how the Circular Economy can continue to be promoted in the literature as a tool for achieving Sustainable Development.

In relation, this also draws attention to the point that within the Circular Economy literature, there have been few attempts to use indicators to measure the success regarding the three aspects of Sustainable Development. Of the efforts to do so relating to social equity, GDP has been at the forefront. For example, Feng et al., (2007) suggest that the implementation of the Circular Economy in certain regions of China has seen a significant increase in GDP which has subsequently improved social equity. However, whilst it is argued that GDP is a relevant indicator of economic growth, there is far less support for it being used as a measure of social equity. On the contrary, it is widely accepted that an increase in GDP is not adequate proxy for an increase in social equity (Daly, 2002). As such this further emphasises the reoccurring point that much of the Circular Economy literature has failed to address many problems that have been popularised in the Sustainable Development literature including those highlighting the difficulty in creating an indicator of Sustainable Development (Holden et al., 2017).

Therefore, it is apparent that not only is there an unclear consensus as to how the Circular Economy will promote social equity, there are also unsubstantiated suggestions of the possible social benefits the Circular Economy will provide. The lack of awareness of the complexities of creating an indicator that can adequately and accurately encapsulate the three dimensions of Sustainable Development have allowed the Circular Economy discourse to advance in different directions. This section has provided further support to suggest that for the most part, the Circular Economy literature has uncovered the same pitfalls that other models attempting to achieve Sustainable Development have uncovered.

\subsection{Implementation}

The penultimate section of this review concerns the implementation of the Circular Economy. As highlighted in Section 2.2, the uptake of the concept has occurred globally and across a variety of scales ranging from government initiatives to business-led approaches. However, the 
Sustainable Development literature has long emphasised the challenges of implementing strategies or tools that attempt to achieve Sustainable Development thus indicating that Circular Economy strategies seeking to achieve Sustainable Development could be facing similar obstacles (Simon, 1989; Jaiyesimi, 2016).

Amongst these challenges, there is a concern as to whether Sustainable Development initiatives are more effective if they are implemented using either a "top down" or "bottom up" approach and as highlighted by Cairns (2003), there are obstacles to both. A "top down" approach, which is commonly characterised as implementation enforced by government institutions or their equivalents, is often criticised for its inability to encompass the perspectives and values of all stakeholders involved and its subsequent lack of support which in turn leads to inadequate implementation (Cairns, 2003). On the other hand, a "bottom up" approach, which is generally identified as initiatives advanced from the individual level, is reprimanded for its inability to inflict widespread implementation (Cairns, 2003). Moreover, the similarity between both approaches when trying to implement tools for Sustainable Development is that they both encounter conflicts with other stakeholders (Cairns, 2003).

In contrast, as suggested by Simon (1989: 1382), the most effective methods of addressing conflicts - concerning implementing projects that aim to achieve Sustainable Development - are those that are collaborative and involve the "exchange of responsibilities, needs and control in the planning process" and thus an amalgamation of "top down" and "bottom up" approaches. The author argues that through the inclusion of all stakeholders affected by the development, there is increased support for the development and implementation of a project. This is also supported by Loorbach and Rotsmans (2006: 2) who suggest that "a practical implementation of Sustainable Development has to incorporate the inherent conflicts between the values, ambitions, and goals of a multitude of stakeholders". This therefore emphasises that tools seeking to bring about Sustainable Development require collaborative approaches and will be less likely to succeed in doing so through adopting exclusively "top down" or "bottom up" strategies.

In relation to the Circular Economy, at the time of writing, there has been no comprehensive review of how the Circular Economy is being implemented globally nor how the methods for implementation pertain to accomplishing Sustainable Development. Nevertheless, there have been several attempts at local reviews including specific case studies of how the Circular Economy is being implemented, an example of this being the review of the "top down" led Circular Economy implementation in Dalian, China (Geng et al., 2009). Within the review, the authors discuss multiple environmental issues troubling the city and as a result explain the need for "a Circular Economy model to be implemented as a new Sustainable Development model that has the ability 
to overcome the current dilemma" (Geng et al., 2009: 997). However, the authors also highlight the challenges to successfully implementing the Circular Economy with the main obstacles being unspecified roles, lack of government coordination and low levels of public awareness and participation. Therefore, despite the Circular Economy being implemented through a "top down" approach, it is evident that the implementation is suffering from the aforementioned complications that collaborative approaches avoid.

Conversely, Lieder and Rashid (2016: 42) support the need for "a concurrent top-down and bottom-up approach" for implementing the Circular Economy on a larger scale and emphasise the assumption that "inverse motivations exist among the stakeholders of $\mathrm{CE}$ which need to be aligned and converged". The authors further acknowledge the need to include a collaboration of policy makers, governmental bodies and manufacturing industries if a Circular Economy implementation strategy is to be considered feasible. However, whilst the authors recognise this, they do not observe the influence nor involvement of additional stakeholders such as consumers and how they are incorporated into the implementation of the Circular Economy. Moreover, it could be argued that the economic growth aspect of the Circular Economy relies on the consumption of secondary products and that lack of engagement with these stakeholders in the implementation phase could result in an absence of support. As such, a complete collaboration of stakeholders involves not simply multi-stakeholder engagement, but the inclusion of a plurality of perspectives that encompasses all stakeholders involved.

Furthermore, it is important to note that whilst a collaborative approach that involves the sharing of knowledge and responsibilities between concerned stakeholders may not be guaranteed to improve the success of implementing the Circular Economy as a tool for Sustainable Development, based on the current reviews found in the literature, it is clear that a plurality of perspectives and multi-stakeholder engagement is desired. Therefore, the scarcity of reviews and how they seek to implement the Circular Economy must be addressed before the formation of any strategy concerning how Sustainable Development can be achieved through a successfully implemented Circular Economy.

\section{Discussion and conclusions}

This review of Circular Economy literature has emphasised that despite being promoted as a tool for Sustainable Development, amongst the current discourse, it is unclear if the Circular Economy can promote economic growth whilst simultaneously protecting the natural environment and improving social equity for this generation and those to come, thus challenging this propagation. This has been highlighted in relation to concerns regarding its conceptual 
understanding, biophysical barriers, its implementation and its relationship with social equity as emphasised in Table 1. In addition, this has indicated that through its current comprehension, the Circular Economy may result in outcomes similar to that of the linear economy, thus leaving the two undifferentiated in this respect. Furthermore, although several authors have acknowledged that the model cannot achieve Sustainable Development and that instead it is more appropriate to advocate it as a more sustainable model than the current linear economy, there is no guarantee of this. Therefore, it is not only uncertain as to whether the Circular Economy can be a successful tool for Sustainable Development, but also whether it is a more sustainable model than the linear economy.

\section{[Figure 2]}

As such, for the Circular Economy to advance as a model that can lead to Sustainable Development, this review complements previous suggestions for how future research can proceed in doing so whilst also presenting new ideas to be considered. This includes backing for the suggestion put forward by Kirchherr et al., (2017: 230) that a "distinction between ideal and subverted CE definitions" is needed as a continuation of subverted definitions will allow the Circular Economy to continue with a concealed understanding of what it can achieve. Therefore, this will involve not only the need for the creation of definitions that fully represent the way in which the Circular Economy can promote Sustainable Development, but also drawing attention to definitions that do not do so and as highlighted in Section 3.1, this must be done across disciplines to make a consistent change.

Secondly, as supported by Merli et al., (2018), the absence of research considering how the Circular Economy addresses social welfare suggests that this must be a priority. This will require a joint effort of disciplines to both understand how the Circular Economy will improve social equity and to develop new indicators that can adequately measure these improvements. In addition, also promoted by Merli et al., (2018), more attention must be devoted to developing new strategies for altering patterns of production and consumption that allow the Circular Economy to eliminate a reliance on the extraction of virgin materials whilst promoting the consumption of secondary materials. This will involve more novel research as most alteration studies are focused on the reduction of both production and consumption (Jackson and Senker, 2011). However as highlighted in Section 3.3, consumption of secondary materials is essential to continued economic growth and the success of the Circular Economy hence the need for innovative thinking. 
Followingly, further scientific research is required to support verifications that the Circular Economy can have negligible effects on the natural environment through understanding the indirect effects of a Circular Economy including the "rebound effects" and the after effect of material flows (Korhonen et al., 2018a). In doing so, greater clarification can be given to the extent to which the Circular Economy can be considered closed-loop and also to fully discover how its environmental impact differs from that of the linear economy.

It is evident that a literature review concerning the implementation of the Circular Economy with a focus on methods for application that will result in Sustainable Development is in demand. As highlighted, there is no consensus as to how best to implement the Circular Economy nor how all stakeholders can be equally incorporated. Correspondingly, this will require a unified approach across disciplines to ensure that notions of implementation that adhere to the principles of Sustainable Development are pursued with a similar understanding. It will therefore involve a collaboration between fields of enquiry including ecological economics, industrial ecology and cleaner production which are at the forefront of Circular Economy research as well as new disciplines such as behavioural economics which could assist in enhancing the development of the Circular Economy. Lastly, the purview of this review was to bring to the fore some of the primary issues of how the Circular Economy is failing to meet the requirements for Sustainable Development. Therefore, this review recognises that there may be many other aspects of the Circular Economy relating to Sustainable Development that have not been discussed. As such this emphasises the need for further reviews regarding the two concepts to uncover these possible unknown aspects and provide solutions for how they can be altered to legitimise the Circular Economy as a tool for achieving Sustainable Development.

\section{References}

Allwood, J.M. (2014). "Squaring the Circular Economy: The Role of Recycling Within a Hierarchy of Material Management Strategies", in E. Worrel and M.A. Reuter (eds), Handbook of Recycling State-of-the-art for practitioners, analysts, and scientists. Waltham, Elsevier.

Anand, S. and Sen, A. (2000). Human Development and Economic Sustainability. World Development, 28(12), pp.2029-2049.

Andersen, M. (2006). An introductory note on the environmental economics of the circular economy. Sustainability Science, 2(1), pp.133-140.

Baker, S. (2012). Politics of sustainable development. Routledge.

Benyus, J.M. (1997). Biomimicry - Innovation Inspired by Nature. William Morrow and Company, New York, 
Blewitt, J. (2014). Understanding sustainable development. Routledge.

Bonviu, F. (2014). The European economy: from a linear to a circular economy. Romanian J. Eur. Aff., 14, p.78.

Boulding, K. (1966). The economics of the coming spaceship earth. Environmental Quality Issues in a Growing Economy.

Braungart, M., McDonough, W. and Bollinger, A. (2007). Cradle-to-cradle design: creating healthy emissions - a strategy for eco-effective product and system design. Journal of Cleaner Production, 15(13-14), pp.1337-1348.

Broman, G.I. and Robèrt, K.H. (2017). A framework for strategic sustainable development. Journal of Cleaner Production, 140, pp.17-31.

Brundtland, G. (1987). Report of the World Commission on environment and development:" our common future.". United Nations.

Büchs, M. and Koch, M. (2017). Capitalist Development and the Growth Paradigm. In Postgrowth and Wellbeing, pp. 9-24. Palgrave Macmillan. Cham.

Cairns, J. (2003). Integrating top-down/bottom-up sustainability strategies: an ethical challenge. Ethics in Science and Environmental Politics, 3, pp.1-6.

Ciraig.org. (2017). International Reference Centre for the Life Cycle of Products, Processes and Services. [online] Available at: http://www.ciraig.org/en/v.php?id=396\&locale=en\&year=2015\&type $=2$ [Accessed 22 Nov. 2017].

Connelly, S. (2007). Mapping sustainable development as a contested concept. Local Environment, 12(3), pp.259-278.

Costanza, R., Cumberland, J., Daly, H., Goodland, R., Norgaard, R., Kubiszewski, I. and Franco, C. (2014). An introduction to ecological economics. CRC Press.

Dale, A. and Hill, S. (2001). At the edge: Sustainable development in the 21st century. UBC Press.

Daly, H. (2002). Reconciling the economics of social equity and environmental sustainability. Population \& Environment, 24(1), pp.47-53.

Dasgupta, P. and Heal, G. (1974). The optimal depletion of exhaustible resources. The review of economic studies, 41 , pp.3-28

Dawe, N. and Ryan, K. (2003). The faulty three-legged-stool model of sustainable development. Conservation Biology, 17(5), pp.1458-1460.

Ellen MacArthur Foundation (2018). [online] Ellenmacarthurfoundation.org. Available at: https://www.ellenmacarthurfoundation.org/assets/downloads/publications/EllenMacArthur-Foundation-Towards-the-Circular-Economy-vol.1.pdf [Accessed 7 Oct. 2018]. 
Ellen MacArthur Foundation (2017). Circular Economy - UK, USA, Europe, Asia \& South America The Ellen MacArthur Foundation. [online] Available at: https://www.ellenmacarthurfoundation.org/ [Accessed 20 Nov. 2017].

Engelman, R. (2013). Beyond sustainababble. In State of the World 2013 (pp. 3-16). Island Press. Center for Resource Economics.

Esposito, M., Tse, T. and Soufani, K. (2017). Is the Circular Economy a New Fast- Expanding Market?. Thunderbird International Business Review, 59(1), pp.9-14.

European Commission, (2014). Towards a circular economy: a zero waste programme for Europe. Communication From the Commission to the European Parliament. the Council, the European Economic and Social Committee and the Committee of the Regions, Brussels European Commission, (2015). Closing the Loop - An EU Action Plan for the Circular Economy. Communication From the Commission to the European Parliament. The Council, the European Economic and Social Committee and the Committee of the Regions.Feng, W., Mao, Y., Chen, H. and Chen, C. (2007). Study on development pattern of circular economy in chemical industry parks in China. Modern Chemical Industry, 27(3), p.7.

Feng, ZJ and Yan NL (2007). Putting a circular economy into practice in China. Sustainability Science, 2(1), pp.95-101.

Flint, R. (2013). Basics of sustainable development. In Practice of Sustainable Community Development. Springer, New York, pp, 25-54.

Frosch, R. and Gallopoulos, N. (1989). Strategies for manufacturing. Scientific American, 261(3), pp.144-152.

Haas, W., Krausmann, F., Wiedenhofer, D., \& Heinz, M. (2015). How circular is the global economy?: An assessment of material flows, waste production, and recycling in the European Union and the world in 2005. Journal of Industrial Ecology, 19(5), 765-777.

Geissdoerfer, M., Savaget, P., Bocken, N. and Hultink, E. (2017). The Circular Economy - A new sustainability paradigm? Journal of Cleaner Production, 143, pp.757-768.

Geng, Y. and Doberstein, B. (2008). Developing the circular economy in China: Challenges and opportunities for achieving 'leapfrog development'. International Journal of Sustainable Development \& World Ecology, 15(3), pp.231-239.

Geng, Y., Zhu, Q., Doberstein, B. and Fujita, T. (2009). Implementing China's circular economy concept at the regional level: A review of progress in Dalian, China. Waste Management, 29(2), pp.996-1002. 
Geng, Y., Fu, J., Sarkis, J. and Xue, B. (2012). Towards a national circular economy indicator system in China: an evaluation and critical analysis. Journal of Cleaner Production, 23(1), pp.216-224.

Georgescu-Roegen, N. (1971). The entropy law and the economic problem. Harvard University. Harvard.

Ghisellini, P., Cialani, C. and Ulgiati, S. (2016). A review on circular economy: the expected transition to a balanced interplay of environmental and economic systems. Journal of Cleaner Production, 114, pp.11-32.

Graedel, T. and Allenby, B. (2003). Industrial ecology. Pearson College Division.

Gillingham, K., Kotchen, M., Rapson, D. and Wagner, G. (2013). Energy policy: The rebound effect is overplayed. Nature, 493(7433), pp.475-476.

Hertwich, E. (2005). Consumption and the rebound effect: An industrial ecology perspective. Journal of industrial ecology, 9(1- 2), pp.85-98.

Hoekstra, A. and Wiedmann, T. (2014). Humanity's unsustainable environmental footprint. Science, 344(6188), pp.1114-111

Holden, E., Linnerud, K., Banister, D., Schwanitz, V. and Wierling, A. (2017). The Imperatives of Sustainable Development: Needs, Justice, Limits. Routledge.

Jackson, T. and Senker, P. (2011). Prosperity without Growth: Economics for a Finite Planet. Energy \& Environment, 22(7), pp.1013-1016.

Jaiyesimi, R. (2016). The Challenge of Implementing the Sustainable Development Goals in Africa: The Way Forward. African Journal of Reproductive Health, 20(3), pp.13-18.

Jelinski, L.W., Graedel, T.E., Laudise, R.A., McCall, D.W., Patel, C.K.N. (1992). Industrial ecology: concepts and approaches. Proc. Natl. Acad. Sci. 89, 793-797.

Kallis, G. (2011). In defence of degrowth. Ecological Economics, 70(5), pp.873-880.

Kirchherr, J., Reike, D. and Hekkert, M. (2017). Conceptualizing the Circular Economy: An Analysis of 114 Definitions. Resources, Conservation and Recycling, 127, pp.221-232

Korhonen, J., Honkasalo, A. and Seppälä, J. (2018a). Circular Economy: The Concept and its Limitations. Ecological Economics, 143, pp.37-46.

Korhonen, J., Nuur, C., Feldmann, A. and Birkie, S. (2018b). Circular economy as an essentially contested concept. Journal of Cleaner Production, 175, pp.544-552.

Lieder, M. and Rashid, A. (2016). Towards circular economy implementation: a comprehensive review in context of manufacturing industry. Journal of Cleaner Production, 115, pp.36-51.

Lélé, S. (1991). Sustainable development: A critical review. World Development, 19(6), pp.607-621. 
Loorbach, D. and Rotmans, J. (2006). Managing transitions for sustainable development. Understanding industrial transformation, pp.187-206.

Lyle, J. (1996). Regenerative design for sustainable development. John Wiley \& Sons.

Mathews, J. and Tan, H. (2011). Progress toward a circular economy in China. Journal of industrial ecology, 15(3), pp.435-457.

McMillan, C., Skerlos, S. and Keoleian, G. (2012). Evaluation of the Metals Industry's Position on Recycling and its Implications for Environmental Emissions. Journal of Industrial Ecology, 16(3), pp.324-333.

Meadowcroft, J. (2000). Sustainable development: a new (ish) idea for a new century? Political Studies, 48(2), pp.370-387.

Meadows, D. Meadows, D., Randers, J. and Behrens, W. (1972). The limits to growth. New York.

Mebratu, D. (1998). Sustainability and sustainable development: historical and conceptual review. Environmental impact assessment review, 18(6), pp.493-520.

Merli, R., Preziosi, M. and Acampora, A. (2018). How do scholars approach the circular economy? A systematic literature review. Journal of Cleaner Production, 178, pp.703-722.

Moir, S. and Carter, K. (2012). Diagrammatic representations of sustainability-a review and synthesis. In Procs 28th Annual ARCOM Conference, pp. 3-5.

Moreau, V., Sahakian, M., van Griethuysen, P. and Vuille, F. (2017). Coming Full Circle: Why Social and Institutional Dimensions Matter for the Circular Economy. Journal of Industrial Ecology, 21(3), pp.497-506.

Murray, A., Skene, K. and Haynes, K. (2017). The circular economy: An interdisciplinary exploration of the concept and application in a global context. Journal of Business Ethics, 140(3), pp.369-380.

Pauliuk, S., Wang, T. and Müller, D. (2011). Moving Toward the Circular Economy: The Role of Stocks in the Chinese Steel Cycle. Environmental Science \& Technology, 46(1), pp.148-154.

Pauliuk, S. (2018). Critical appraisal of the circular economy standard BS 8001:2017 and a dashboard of quantitative system indicators for its implementation in organizations. Resources, Conservation and Recycling, 129, pp.81-92.

Pearce, D. and Turner, R. (1990). Economics of natural resources and the environment. JHU Press.

Redclift, M. (2005). Sustainable development (1987-2005): an oxymoron comes of age. Sustainable Development, 13(4), pp.212-227.

Rees, W. (2010). What's blocking sustainability? Human nature, cognition, and denial. Sustainability: Science, Practice and Policy, 6(2), pp.13-25.

Rist, G. (2007). Development as a buzzword. Development in Practice, 17(4-5), pp.485-491. 
Robinson, J. (2004). Squaring the circle? Some thoughts on the idea of sustainable development. Ecological Economics, 48(4), pp.369-384.

Rogers, P., Jalal, K. and Boyd, J. (2012). An introduction to sustainable development. Earthscan.

Sachs, J. (2015). The age of sustainable development. New York: Columbia University press.

Sauvé, S., Bernard, S. and Sloan, P. (2016). Environmental sciences, sustainable development and circular economy: Alternative concepts for trans-disciplinary research. Environmental Development, 17, pp.48-56.

Schaefer, A. and Crane, A. (2005). Addressing Sustainability and Consumption. Joumal of Macromarketing, 25(1), pp.76-92.

Schneider, F., Kallis, G. and Martinez-Alier, J. (2010). Crisis or opportunity? Economic degrowth for social equity and ecological sustainability. Introduction to this special issue. Journal of cleaner production, 18(6), pp.511-518.

Schroeder, P., Anggraeni, K. and Weber, U. (2018). The Relevance of Circular Economy Practices to the Sustainable Development Goals. Journal of Industrial Ecology.

Simon, D. (1989). Sustainable Development: Theoretical Construct or Attainable Goal?. Environmental Conservation, 16(01).

Solow, R. (1974). Intergenerational equity and exhaustible resources. The review of economic studies, 41, pp.29-45.

Stahel, W. (2010). The Performance Economy. Palgrave Macmillan.

Stahel WR (2016) The circular economy. Nature 531, 7595

Stevenson, R. and Evans, J. (2004). Editorial to: Cutting across interests: cleaner production, the unified force of sustainable development. Journal of Cleaner Production, 12(3), pp.185-187.

Stiglitz, J. (1974). Growth with exhaustible natural resources: efficient and optimal growth paths. The review of economic studies, 41, pp.123-137.

Su, B., Heshmati, A., Geng, Y. and Yu, X. (2013). A review of the circular economy in China: moving from rhetoric to implementation. Journal of Cleaner Production, 42, pp.215-227.

Tukker, A. (2015). Product services for a resource-efficient and circular economy - a review. Journal of Cleaner Production, 97, pp.76-91.

United Nations (2012). Transforming our W orld: The 2030 Agenda for Sustainable Development. [online] Unfpa.org. Available at: https://www.unfpa.org/resources/transforming-our-world2030-agenda-sustainable-development [Accessed 7 Oct. 2018].

Vlek, C. and Steg, L. (2007). Human Behavior and Environmental Sustainability: Problems, Driving Forces, and Research Topics. Journal of Social Issues, 63(1), pp.1-19.

Webster, K. (2015). The circular economy: A wealth of flows. Ellen MacArthur Foundation Publishing. 
Xue, B., Chen, X., Geng, Y., Guo, X., Lu, C., Zhang, Z. and Lu, C.Y. (2010). Survey of officials' awareness on circular economy development in China: based on municipal and county level. Resources, Conservation and Recycling, 54(12), pp.1296-1302.

Young, S. (1997). Community-based partnerships and sustainable development. The Politics of Sustainable Development, pp.217-236.

Yuan, Z., Bi, J. and Moriguichi, Y. (2008). The Circular Economy: A New Development Strategy in China. Journal of Industrial Ecology, 10(1-2), pp.4-8.

Zink, T. and Geyer, R. (2017). Circular Economy Rebound. Journal of Industrial Ecology, 21(3), pp.593-602.

\footnotetext{
${ }^{1}$ The way in which the Circular Economy is discussed varies across the literature. Its description ranges from industrial model, economic model, industrial production model, economic development strategy, industrial flow model, economic system, production and consumption model. This all stems from the ambiguity of defining the Circular Economy. I have therefore referred to it at the start and Section 2.2 as a "material and energy flow model" with the reasoning explained in Section 2.2.

${ }^{2}$ Press releases and FAQs documents for the SDG repeat the passage: "For sustainable development to be achieved, it is crucial to harmonize three core elements. economic growth, social inclusion and environmental protection. These elements are interconnected and all are crucial for the well-being of individuals and societies." Thus highlighting the continued connection with the three pillars model in the current SDG framework. E.g. see Press Kit for the Sustainable Development Summit 2015: http://www.fao.org/3/a-az715e.pdf and SGD FAQs https://www.un.org/sustainabledevelopment/development-agenda/
} 